\title{
PERAN CUSTOMER SATISFACTION MEMODERASI PENGARUH RELATIONSHIP MARKETING TERHADAP CUSTOMER LOYALTY (Studi pada PT. Bank BRI Cabang Gatot Subroto Denpasar)
}

\author{
Dewa Nyoman Wiesdya Danabrata Parsana ${ }^{1}$ \\ I Gusti Ayu Ketut Giantari ${ }^{2}$
}

${ }^{1,2}$ Fakultas Ekonomi dan Bisnis Universitas Udayana, Denpasar, Bali-Indonesia email: dewawiesdya@gmail.com

\begin{abstract}
ABSTRAK
Tujuan penelitian ini adalah untuk menjelaskan pengaruh customer satisfaction dan relationship marketingterhadap customer loyalty serta untuk menjelaskan customer satisfactionmemoderasi pengaruh relationship marketingterhadap customer loyalty pada PT. Bank BRI Cabang Gatot Subroto Denpasar. Penelitian ini dilakukan di PT. Bank BRI Cabang Gatot Subroto Denpasar. Populasi penelitian ini adalahseluruh nasabah PT. Bank BRI Cabang Gatot Subroto Denpasar. Pengambilan sampel menggunakan metode purposive sampling. Teknik analisis data yang digunakan adalah MRA.Hasil penelitian menunjukkan bahwa relationship marketing dan customer satisfaction berpengaruh positif dan signifikan terhadap customer loyalty pada PT. Bank BRI Cabang Gatot Subroto Denpasar.Customer satisfactionmemoderasi pengaruh positif relationship marketingterhadap customer loyalty pada PT. Bank BRI Cabang Gatot Subroto Denpasar. Implikasi penelitian menunjukan bahwa relationship marketing dan customer satisfaction nasabah sampai saat ini sudah dapat dikategorikan dalam predikat baik, akan tetapi manajemen harus berusaha memberikan yang terbaik kepada nasabah agar dapat menjaga dan meningkatkan loyalitas nasabah.

Kata kunci: customer satisfaction, relationship marketing, customer loyalty
\end{abstract}

\begin{abstract}
The purpose of this study is to explain the effect of customer satisfaction and relationship marketing on customer loyalty and to explain customer satisfaction moderating the effect of relationship marketing on customer loyalty at PT. Bank BRI Branch Gatot Subroto Denpasar. This research was conducted at PT. Bank BRI Branch Gatot Subroto Denpasar. The study population was all customers of PT. Bank BRI Branch Gatot Subroto Denpasar. Sampling using a purposive sampling method. The data analysis technique used is MRA. The results showed that relationship marketing and customer satisfaction had a positive and significant effect on customer loyalty at PT. Bank BRI Branch Gatot Subroto Denpasar. Customer satisfaction moderates the positive effect of relationship marketing on customer loyalty at PT. Bank BRI Branch Gatot Subroto Denpasar. The research implications show that customer relationship marketing and customer satisfaction to date can be categorized as good, but management must try to give the best to customers in order to maintain and increase customer loyalty.
\end{abstract}

Keywords: customer satisfaction, relationship marketing, customer loyalty 


\section{PENDAHULUAN}

Dunia perbankan pada saat ini menjadi bahan perbincangan yang cukup marak terdengar, baik di media cetak maupun di media elektronik. Kondisi dunia perbankan di Indonesia telah mengalami banyak kemajuan dan banyak berdiri bank-bank baru. Bank dalam kegiatannya secara umum hanya dapat dijalankan apabila dasar beroperasinya bank telah terpenuhi dengan baik (Amalana, 2016). Dasar beroperasinya bank adalah kepercayaan, sehingga bank merupakan lembaga keuangan yang menjadi tempat bagi perusahaan, badan pemerintah dan pihak swasta, maupun masyarakat dalam menyimpan dana atau tabungannya. Oleh karena itu perbankan dituntut untuk semakin meningkatkan pelayanannya, mengingat nasabah semakin meningkat mobilitas dan kebutuhannya. Hal ini dimaksudkan untuk memenuhi kepuasan nasabah serta memelihara kepercayaan, kesetiaan dan loyalitas masyarakat terhadap dunia perbankan (Apriliani et al, 2014).

Handayani \& Ida (2017) menyatakan konsep loyalitas konsumen atau kesetiaan konsumen tidak terbentuk dalam waktu singkat tetapi melalui proses belajar dan berdasarkan hasil pengalaman dari konsumen itu sendiri dari pembelian konsisten sepanjang waktu. Bila dari pengalamannya, konsumen tidak mendapatkan merek yang memuaskan maka tidak akan berhenti untuk mencoba merek-merek yang lain sampai ia mendapatkan produk atau jasa yang memenuhi kriteria mereka (Luhgiatno \& Endang, 2016).

Shahiida et al., (2014) menyatakan salah satu strategi yang dapat diterapkan oleh perusahaan dalam mempertahankan loyalitas nasabah adalah menciptakan hubungan (relationship) antara perusahaan dengan nasabah. Strategi menciptakan hubungan dengan nasabah ini dikenal dengan relationship marketing. Wachyudi (2018) mendefinisikan relationship marketing sebagai pengenalan setiap nasabah secara lebih dekat dengan menciptakan komunikasi dua arah dengan mengelola suatu hubungan yang saling menguntungkan antara nasabah dan perusahaan. Apriliani et al., (2014) mengatakan faktor yang mendorong relationship marketing adalah trust, commitment, communication and conflict handling.

Meningkatkan loyalitas nasabah tentu tidak dapat dipisahkan dari kepuasan nasabah itu sendiri. Bagi perusahaan perbankan suatu kepuasan nasabah sangat diperlukan khususnya dalam rangka eksistensi perusahaan tersebut, sehingga nasabah tersebut akan tetap menggunakan jasa perusahaan tersebut (Pratiwi dkk, 2014). Menurut Silvida (2016) kepuasan adalah tingkat perasaan seseorang setelah membandingkan kinerja/hasil yang dirasakannya dengan harapannya. Pratiwi dkk., (2014) membuktikan kepuasan pelangganmemiliki pengaruh positif dalam meningkatkan loyalitas konsumen (customer loyalty).

Kotler \& Keller (2007) menyatakan loyalitas pelanggan merupakanv fungsi kepuasan dimana pelanggan setia untuk berkontribusi terhadap profitabilitas perusahaan dengan pembelanjaan lebih banyak terhadap produk perusahaan dan jasa, melalui pembelian ulang, dan dengan merekomendasikannya kepada konsumen lain. Adapun indikator nasabah yang loyal menurut Hurriyati (2010) adalah melakukan pembelian secara teratur, membeli diluar lini produk/jas, 
merekomendasikan produk lain, menunjukkan kekebalan dari daya tarik produk sejenis dari pesaing.

Kotler \& Armstrong (2012) menyatakan pengertian dari relationship marketing adalah suatu proses untuk menciptakan, mempertahankan dan meningkatkan hubungan-hubungan yang kuat dengan para pelanggan dan stakeholder lainnya. Menurut Tjiptono (2011:417) tujuan sebuah perusahaan menerapkan relationship marketing adalah agar perusahaan tersebut dapat membangun dan mempertahankan basis nasabah yang memiliki relationship commitment kuat dan profitable bagi perusahaan. Indikator Relationship Marketing diukur dengan empat indikator menurut Alrubaiee \& Nahla (2010) adalah kepercayaan (trust), komitmen (commitment), komunikasi (communication), penanganan keluhan (conflict handling).

Menurut Kotler \& Keller (2007:177) kepuasan nasabah adalah perasaan senang atau kecewa seseorang yang muncul setelah membandingkan kinerja (hasil) yang diharapkan. Stephen et al., (2014) kepuasan nasabah merupakan suatu tanggapan emosional pada evaluasi terhadap pengalaman konsumsi suatu produk atau jasa. Ada empat indikator yang banyak digunakan dalam mengukur kepuasan nasabah menurut Martini (2013) yaitu puas dengan sistem keluhan dan saran, puas dengan adanya sistem go shopping, puas dengan adanya lost customers analysis, puas dengan survei kepuasan nasabah.

Berdasarkan latar belakang yang telah diuraikan sebelumnya, maka dapat dirumuskan pokok permasalahan penelitian ini adalah sebagai berikut: 1)Bagaimana pengaruh relationship marketing terhadap customer loyalty pada PT. Bank BRI Cabang Gatot Subroto Denpasar? 2)Bagaimana pengaruh customer satisfaction terhadap customer loyalty pada PT. Bank BRI Cabang Gatot Subroto Denpasar? 3) Apakah customer satisfaction memoderasi pengaruh relationship marketing terhadap customer loyalty pada PT. Bank BRI Cabang Gatot Subroto Denpasar?. Sedangkan tujuan penelitian ini adalah sebagai berikut: 1)Untuk menjelaskan pengaruh relationship marketing terhadap customer loyalty pada PT. Bank BRI Cabang Gatot Subroto Denpasar. 2)Untuk menjelaskan pengaruh customer satisfaction terhadap customer loyalty pada PT. Bank BRI Cabang Gatot Subroto Denpasar. 3)Untuk menjelaskan customer satisfaction memoderasi pengaruh relationship marketing terhadap customer loyalty pada PT. Bank BRI Cabang Gatot Subroto Denpasar.

Manfaat penelitian ini terdiri dari manfaat teoritis dan manfaat empiris. Manfaat teoritis dalam penelitian ini yaitu: 1)Pengembangan Ilmu pemasaran yang berkaitan dengan perilaku konsumen, terutama dalam bidang perilaku individu antara lain customer satisfaction, relationship marketing dan customer loyalty. 2)Sebagai perluasan pemahaman tentang konsep perilaku konsumen sebagai individu yang memiliki kecenderungan dalam proses meningkatkan customer satisfaction dan customer loyalty. Sedangkan manfaat empiris dalam penelitian ini yaitu 1)Produsen produk organik dalam memahami kecenderungan konsumen sebagai individu dalam melakukan pembelian. 2)Penelitian ini diharapkan dapat memberikan manfaat bagi PT. Bank BRI Cabang Gatot Subroto Denpasar, dalam pengambilan kebijakan untuk mempertahankan customer satisfaction dan customer loyalty pada nasabahnya. 
Customer loyalty atau loyalitas nasabah merupakan aset yang tak ternilai harganya bagi perusahaan. Nasabah yang loyal akan memberikan keuntungan yang lebih baik pada perusahaan. Sikap dan loyalitas nasabah terhadap suatu merek sangat ditentukan oleh relationship marketing yang mamp diciptakan oleh perusahaan (Kotler \& Keller, 2007:146).

Beberapa penelitian menyebutkan relationship marketing memiliki pengaruh terhadap loyalitas nasabah. Penelitian Arina (2016) yang membuktikan relationship marketing memiliki pengaruh positif dalam meningkatkan loyalitas konsumen. Birgitta (2015) dalam penelitiannya membukitkan relationship marketing secara positif mempengaruhi customer loyalty. Laith dan Nahla (2010) menyatakan relationship marketing memiliki pengaruh positif dalam meningkatkan loyalitas konsumen. Nagasimha (2016) membuktikan ada pengaruh positif relationship marketing dalam meningkatkan customer loyalty. Fitri et al. (2014) menegaskan variabel relationship marketing memiliki pengaruh positif dalam meningkatkan loyalitas konsumen. Berdasarkan hasil penelitian tersebut, diajukan hipotesis pertama sebagai berikut.

$\mathrm{H}_{1}$ : Relationship marketing berpengaruh positif dan signifikan terhadap customer loyalty.

Kotler \& Keller (2007:67) menjelaskan customer satisfaction atau kepuasan nasabah mengarah kepada profitabilitas, pelanggan yang puas akan menciptakan relationship yang kuat dan mengarah pada loyalitas nasabah. Kepuasan pelanggan bersifat dinamis dan terus-menerus diperbaharui melalui produk/jasa baru, pelayanan baru, komunikasi yang lebih berorientasi kepada loyalitas nasabah (Guido et al., 2015).

Beberapa penelitian menyebutkan customer satisfaction atau kepuasan nasabah memiliki pengaruh terhadap customer loyalty. Penelitian Ustantia et al. (2014) yang membuktikan kepuasan pelanggan memiliki pengaruh positif dalam meningkatkan loyalitas konsumen. Budi (2013) dalam penelitiannya membukitkan customer satisfaction secara positif mempengaruhi customer loyalty. Framarz et al. (2013) menyatakan customer satisfaction memiliki pengaruh positif dalam meningkatkan loyalitas konsumen. Silvida (2016) membuktikan ada pengaruh positif kepuasan pelanggan dalam meningkatkan customer loyalty. Fitri et al. (2014) menegaskan variabel customer satisfaction memiliki pengaruh positif dalam meningkatkan loyalitas konsumen. Berdasarkan pemahaman tersebut dapat dirumuskan hipotesis kedua sebagai berikut.

$\mathrm{H}_{2}$ : Customer satisfaction berpengaruh positif dan signifikan terhadap customer loyalty.

Beberapa penelitian menyatakan relationship marketing berpengaruh positif dengan customer loyalty yang dimoderasi oleh customer satisfaction, seperti penelitian Fitri et al. (2014) yang menegaskan bahwa variabel customer satisfaction memoderasi pengaruh relationship marketing terhadap loyalitas konsumen. Budi (2013) dalam penelitiannya membukitkan customer satisfaction mampu memoderasi pengaruh positif relationship marketing terhadap customer loyalty. Sulhida (2015) menyatakan customer satisfaction memoderasi pengaruh relationship marketing terhadap loyalitas konsumen. Zaman et al. (2015) membuktikan customer satisfaction memoderasi pengaruh relationship marketing 
terhadap loyalitas konsumen. Syarief \& Monika (2016) yang membuktikan kepuasan pelanggan memoderasi pengaruh relationship marketing terhadap loyalitas konsumen. Berdasarkan hasil penelitian tersebut, diajukan hipotesis ke empat sebagai berikut.

$\mathrm{H}_{3}$ : Customer satisfaction memoderasi hubungan antara relationship marketing dengan customer loyalty secara positif.

Berdasarkan penelusuran moderasianalisis dan hasil-hasil penelitian terdahulu maka model penelitian dapat digambarkan seperti berikut:

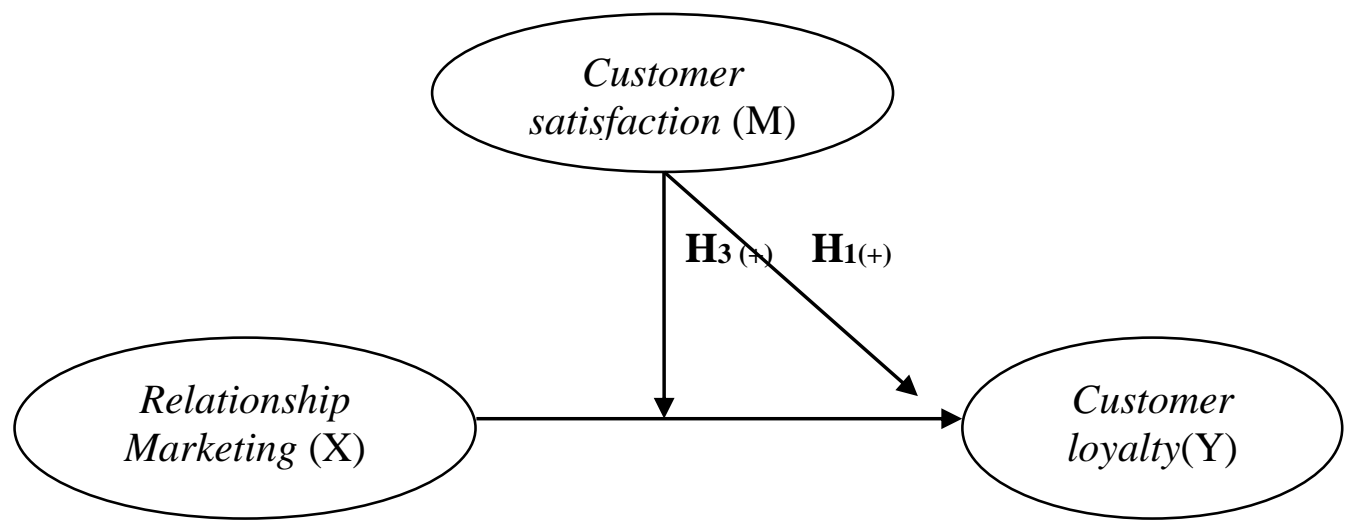

Gambar 1 Model Kerangka Berfikir

Sumber: Hasil Pemikiran Peneliti, 2019

\section{METODE PENELITIAN}

Penelitian ini menggunakan penelitian asosiatif. Lokasi penelitian dilakukan di PT. Bank BRI Cabang Gatot Subroto Denpasar terletak di Jalan Gatot Subroto Barat No.82X. Lokasi ini dipilih karena PT. Bank BRI Cabang Gatot Subroto Denpasar merupakan salah satu Bank BUMN yang memiliki peran lebih menyentuh kepada masyarakat luas karena terkait langsung dengan kegiatan ekonomi keseharian, dengan demikian upaya untuk mengembangkan relationship marketing dengan nasabah.Variabel yang digunakan dalam penelitian ini adalah variabel terikat $(\mathrm{Y})$, variabel bebas $(\mathrm{X})$ dan variabel moderasi $(\mathrm{M})$. Variable terikat (Y) yaitu customer loyalty, variabel bebas (X) yaiturelationship marketing, dan variabel moderasi (M)yaitu customer satisfaction.

Customer loyalty (Y) merupakan sikap pelanggan yang menunjukkan rasa loyal atau selalu setia untuk menggunakan suatu produk/jasa dari PT. Bank BRI. Menurut Hurriyati (2010:130) indikator untuk mengukur loyalitas pelanggan adalah melakukan kunjungan bertransaksi ke PT. Bank BRI secara teratur, menggunakan lini produk/jasa yang dipasarkan PT. Bank BRI, merekomendasikan produk lain dari PT. Bank BRI, menunjukkan kekebalan dari daya tarik produk sejenis dari pesaing lainnya.

Relationship marketing $(\mathrm{X})$ adalah suatu proses yang dilakukan PT. Bank BRI untuk menciptakan, mempertahankan dan meningkatkan hubungan-hubungan 
yang kuat dengan para pelanggan dan stakeholder lainnya. Indikator relationship marketing diukur dengan empat indikator menurut Alrubaiee \& Nahla (2010) yaitu kepercayaan (trust), komitmen (commitment), komunikasi (communication), penanganan keluhan (conflicthandling).

Customer satisfaction (M) adalah perasaan senang atau kecewa seseorang yang muncul setelah membandingkan kinerja (hasil) yang diharapkan. Adapun indikator yang digunakan untuk mengukur kepuasan nasabah menurut Martini (2013) yaitu puas dengan sistem keluhan dan saran, puas dengan adanya sistem go shopping, puas dengan adanya lost customers analysis, puas dengan survei kepuasan nasabah.

Dalam penelitian ini yang menjadi populasi adalah seluruh nasabah PT. Bank BRI Cabang Gatot Subroto Denpasar, yang tidak diketahui jumlahnya.Sampel dalam penelitian ini adalah konsumen yang memenuhi kriteria tertentu yang sesuai dengan penelitian loyalitas nasabah di PT. Bank BRI Cabang Gatot Subroto Denpasar.

Sugiyono (2013:63), mengemukakan bahwa sampel adalah sebagian dari jumlah dan karakteristik yang dimiliki oleh populasi tersebut. Maka sampel dalam penelitian ini adalah konsumen yang memenuhi kriteria tertentu yang sesuai dengan penelitian loyalitas nasabah di PT. Bank BRI Cabang Gatot Subroto Denpasar. Sampel dalam penelitian ini diambil dengan teknik non probability sampling. Yaitu teknik yang tidak memberi peluang atau kesempatan sama bagi setiap unsur atau anggota populasi untuk dipilih menjadi sampel. Teknik pemilihan sampel menggunakan teknik purposive sampling, yaitu teknik penentuan sampel berdasarkan pertimbangan maupun syarat-syarat tertentu. Adapun pertimbangan yang digunakan dalam pengambilan sampel adalah sebagai berikut: 1)Nasabah PT. Bank BRI Cabang Gatot Subroto Denpasar. 2)Responden yang menerima layanan PT. Bank BRI Cabang Gatot Subroto Denpasar.

Untuk memperoleh hasil yang valid dari Kuesioner, diperlukan jumlah sampel responden yang diambil untuk mengisi Kuesioner dapat ditentukan paling sedikit (5-10) x jumlah variabel yang diteliti. Dalam penelitian ini digunakan 12 indikator yang terdiri dari empat pertanyaan variabel loyalitas nasabah, empat pertanyaan dari customer satisfaction dan empat pertanyaan dari relationship marketing sehingga jumlah responden yang digunakan sebagai sampel dalam penelitian ini adalah :

$$
\begin{aligned}
\text { Jumlah sampel } & =\text { Jumlah indikator X } 10 \\
& =12 \times 10 \\
& =120 \text { responden }
\end{aligned}
$$

Sugiyono (2013:86), Skala pengukuran merupakan kesepakatan yang digunakan sebagai acuan untuk menentukan panjang pendeknya interval yang ada dalam alat ukur, sehingga alat ukur tersebut bila digunakan dalam pengukuran akan menghasilkan data kuantitatif. Skala pengukuran yang digunakan adalah Skala Likert, dengan lima angka yang mewakili pendapat atau jawaban tersebut, yaitu: Sangat Setuju $=5$, Setuju $=4$, Cukup Setuju $=3$, Tidak Setuju $=2$, Sangat Tidak Setuju $=1$ 
Skala Likert dipergunakan karena mempunyai beberapa kelebihan seperti kemudahan dalam menyusun pertanyaan, memberi skor, skor yang lebih tinggi tarafnya mudah dibandingkan dengan skor yang lebih rendah, luwes, lebih fleksibel dan mempunyai reliabilitas tinggi dalam mengurutkan berdasarkan intensitas sikap tertentu.

Pengumpulan data dalam penelitian ini menggunakan metode kuesioner dan studi pustaka (library research). Dalam penelitian ini analisis deskriptif digunakan untuk mendeskripsikan objek yang diteliti melalui data sampel atau populasi sebagaimana adanya, tanpa melakukan analsis dan membuat kesimpulan yang berlaku untuk umum (Sugiyono, 2013:112). Analisis deskriptif untuk mengetahui statistik yang digunakan untuk menganalisis data dengan cara mendeskripsikan atau menggambarkan data yang telah terkumpul sebagaimana adanya tanpa bermaksud membuat kesimpulan yang berlaku untuk umum atau generalisasi.

Teknik analisis data yang diterapkan dalam penelitian ini dilakukan secara kuantitatif dengan penekanan data yang bersumber dari data primer, yang mana data tersebut akan diolah kemudian dianalisis. Di samping itu, analisis data akan dilakukan secara kuantitatif dengan menerapkan landasan teori sehingga diharapkan akan memperoleh kesimpulan yang berbobot ilmiah.

Setelah data-data yang dibutuhkan diperoleh, selanjutnya dilakukan analisis sehingga data tersebut lebih berarti. Teknik perhitungan dan analisis data menggunakan Moderating Regression Analysis. Moderating Regression Analysis dinyatakan dalam bentuk regresi berganda dengan persamaan mirip regressi polynomial yang menggambarkan pengaruh nonlinier (Ghozali, 2009; 47) yang dinyatakan dalam bentuk model persamaan sebagai berikut.

$\mathrm{Y}=\alpha+\beta_{1} \mathrm{X}+\beta_{2} \mathrm{M}_{1+} \beta_{3} \mathrm{XM}+\mathrm{e}$

Keterangan:

\begin{tabular}{|c|c|}
\hline $\mathrm{Y}$ & $=$ customer loyalty \\
\hline$\alpha$ & $=$ konstanta \\
\hline$\beta_{1}, \beta_{2,} \beta_{3}$ & $=$ koefisien regresi moderasi masing-masing variabel independen \\
\hline $\mathrm{X}$ & $=$ relationship marketing \\
\hline M & $=$ customer satisfaction \\
\hline $\mathrm{e}$ & $=$ error term yaitu faktor kesalahan dalam penelitian \\
\hline
\end{tabular}

\section{HASIL DAN PEMBAHASAN}

Karakteristik responden penelitian dengan judul peran customer satisfaction memoderasi pengaruh relationship marketing terhadap customer loyalty (Studi Kasus pada PT. Bank BRI Cabang Gatot Subroto Denpasar) dapat dilihat dari beberapa kriteria yaitu: jenis kelamin, umur, lama menjadi nasabah, pendidikan terakhir. Berikut disajikan karakteristik responden penelitian pada Tabel 1. 
Tabel 1.

Karakteristik Responden

\begin{tabular}{llccc}
\hline No & $\begin{array}{c}\text { Karakteristik } \\
\text { Responden }\end{array}$ & Keterangan & Jumlah & $\begin{array}{c}\text { Persentase } \\
\mathbf{\%}\end{array}$ \\
\hline 1 & Jenis Kelamin & Laki-laki & 45 & 37,5 \\
& & Perempuan & 75 & 62,5 \\
& Jumlah & & 120 & 100 \\
2 & Umur & $18-35$ tahun & 49 & 40,8 \\
& $>36-45$ tahun & 26 & 21,7 \\
& $>45-55$ tahun & 30 & 25,0 \\
& $>55$ tahun & 15 & 12,5 \\
& & 120 & 100 \\
3 & Jumlah & 6 tahun & 22 & 18,3 \\
& Lama menjadi & 1 tahun & 36 & 30,0 \\
& pelanggan & 2 tahun & 47 & 39,2 \\
& & $>2$ tahun & 15 & 12,5 \\
& & & 120 & 100 \\
4 & Jumlah & SLTP & 12 & 10,0 \\
& Pendidikan & SLTA & 38 & 31,7 \\
& Terakhir & S1 & 45 & 37,5 \\
& & S.2 & 25 & 20,8 \\
& Jumlah & & 120 & 100 \\
\hline
\end{tabular}

Sumber: Data Primer, diolah (2019)

Tabel 1. menunjukkan bahwa berdasarkan dari jenis kelamin jumlah pelanggan laki-laki sebanyak 45 orang atau 37,5 persen dan perempuan sebanyak 75 orang atau 62,5 persen. Hal ini menunjukkan bahwa jumlah nasabah lebih didominasi oleh pihak perempuan, mengingat nasabah perempuan lebih mengutamakan keamanan dan kenyamanan bertransaksi di PT Bank BRI yang merupakan salah satu Bank BUMN milik pemerintah. Berdasarkan usia, jumlah nasabah terbanyak yaitu yang berumur 18-35 tahun sebanyak 49 orang atau 40,8 persen sedangkan jumlah nasabah yang paling sedikit yakni yang berumur $>55$ tahun yaitu sebanyak 15 orang atau 12,5 persen. Hal ini disebabkan pada usia 1835 tahun merupakan masa produktif dimana kegiatan yang dapat dilakukan masih banyak dibandingkan dengan usia > 55 tahun seperti dalam bidang bisnis yang memiliki perputaran uang yang cukup sering sehingga selalu bertransaksi di perbankan. Berdasarkan lama menjadi nasabah, dapat diketahui sebagian besar menjadi nasabah kurang lebih 2 tahun yaitu sebanyak 47 orang atau 39,2 persen hal tersebut didukung dengan layanan yang diberikan Bank BRI dengan mengutamakan kenyaman nasabah untuk bertransaksi dengan moto senyum, sapa dan salam. Berdasarkan pendidikan terakhir, dapat diketahui sebagian besar adalah S1 yaitu sebanyak 45 orang atau 37,5 persen hal tersebut didukung pada jenjang pendidikan setara S1 ini orang sudah bisa membedakan mana produk perbankan yang sesuai dengan kebutuhannya dalam melaksanakan transaksi sehingga merasa nyaman untuk terus menjadi nasabah di PT Bank BRI.

Data kuesioner yang sudah terkumpul dalam penelitian ini selanjutnya, di uji kelayakannya dengan uji validitas dan reliabilitas. Adapun hasil uji validitas dapat dilihat pada Tabel 2. 
Tabel 2.

Hasil Uji Validitas

\begin{tabular}{|c|c|c|c|c|}
\hline No & Variabel & Indikator & Korelasi & Keterangan \\
\hline \multirow[t]{4}{*}{1} & Relationship Marketing (X) & $\mathrm{X} 1.1$ & 0,399 & Valid \\
\hline & & $\mathrm{X} 1.2$ & 0,385 & Valid \\
\hline & & $\mathrm{X} 1.3$ & 0,569 & Valid \\
\hline & & X1.4 & 0,350 & Valid \\
\hline \multirow[t]{4}{*}{2} & Customer Satisfaction (M) & M1.1 & 0,358 & Valid \\
\hline & & M1.2 & 0,330 & Valid \\
\hline & & M1.3 & 0,651 & Valid \\
\hline & & M1.4 & 0,578 & Valid \\
\hline \multirow[t]{4}{*}{3} & Customer Loyalty (Y) & $\mathrm{Y} 1.1$ & 0,543 & Valid \\
\hline & & $\mathrm{Y} 1.2$ & 0,484 & Valid \\
\hline & & $\mathrm{Y} 1.3$ & 0,453 & Valid \\
\hline & & $\mathrm{Y} 1.4$ & 0,465 & Valid \\
\hline
\end{tabular}

Sumber : Data Primer, diolah (2019)

Tabel 2. dapat dijelaskan bahwa masih-masing indikator variabel memiliki nilai person correlation lebih besar dari 0,30, maka ini berarti indikator/pertanyaan yang digunakan layak digunakan untuk mengukur apa yang seharusnya diukur, dan dapat mengungkap data dari variabel yang diteliti secara tepat.

Rekapitulasi hasil uji reliabilitas instrumen penelitian dapat dilihat pada Tabel 3. yaitu :

Tabel 3.

Hasil Uji Reliabilitas

\begin{tabular}{clcc}
\hline \multirow{2}{*}{ No } & \multicolumn{1}{c}{ Variabel } & $\begin{array}{c}\text { Cronbach's } \\
\text { Alpha }\end{array}$ & Keterangan \\
\hline 1 & Relationship Marketing $(\mathrm{X})$ & 0,607 & Reliabel \\
2 & Customer Satisfaction $(\mathrm{M})$ & 0,611 & Reliabel \\
3 & Customer Loyalty $(\mathrm{Y})$ & 0,602 & Reliabel \\
\hline
\end{tabular}

Sumber : Data Primer, diolah (2019)

Hasil uji reliabilitas yang disajikan dalam Tabel 3. menunjukkan bahwa seluruh instrumen penelitian memiliki koefisien Cronbach's Alpha lebih dari 0,60. Jadi dapat dinyatakan bahwa seluruh variabel telah memenuhi syarat reliabilitas atau kehandalan sehingga dapat digunakan untuk melakukan penelitian.

Untuk mendeskripsikan penilaian rata-rata responden mengenai variabelvariabel dalam penelitian, hasil jawaban responden disesuaikan dengan desain skala pengukuran yang telah ditetapkan kemudian diformulasikan ke dalam beberapa interval kelas. Rumus interval kelas adalah sebagai berikut:

$$
\text { Interval }=\frac{\text { Nilai Tertinggi }- \text { Nilai Terendah }}{\text { Jumlah Kelas }}=\frac{5-1}{5}=0,80
$$


Skor pada penelitian ini memiliki nilai tertinggi maksimal 5 dan terendah minimal 1, sehingga dapat disusun kriteria pengukuran sebagai berikut.

Tabel 4.

Kriteria dan Kategori Penilaian Jawaban kuisioner

\begin{tabular}{cc}
\hline Batas-batas Klasifikasi (Kriteria) & Kategori Penilaian \\
\hline $1,00-1,79$ & Sangat tidak baik \\
$1,80-2,59$ & Tidak baik \\
$2,60-3,39$ & Cukup baik \\
$3,40-4,19$ & Baik \\
$4,20-5,00$ & Sangat baik \\
\hline
\end{tabular}

Data yang ditunjukan Tabel 5. menampilkan proporsi jawaban responden, rata-rata jawaban, dan kriteria penilaian jawaban responden untuk masing-masing pernyataan pada variabel relationship marketing. Adapun datanya adalah sebagai berikut :

Tabel 5.

Hasil Penilaian Responden atas Variabel Relationship Marketing

\begin{tabular}{clccccccc}
\hline No & \multicolumn{1}{c}{ Pernyataan } & STS & TS & N & S & SS & $\begin{array}{c}\text { Rata-rata } \\
\text { Skor }\end{array}$ & $\begin{array}{c}\text { Kategori } \\
\text { Penilaian }\end{array}$ \\
\hline 1 & $\begin{array}{l}\text { Menjalin hubungan } \\
\text { kepercayaan dengan } \\
\text { karyawan PT Bank BRI } \\
\text { Menjaga komitmen }\end{array}$ & 0 & 6 & 21 & 68 & 25 & 3,93 & Baik \\
2 & & & & & & & & \\
yang baik dengan \\
karyawan PT Bank BRI \\
$\begin{array}{l}\text { Menjalin komunikasi } \\
\text { yang baik dengan } \\
\text { karyawan PT Bank BRI }\end{array}$
\end{tabular}

Tabel 5. nilai total rata-rata jawaban responden sebesar 4,03 yaitu berada pada kategori baik. Hal ini memberikan informasi bahwa PT Bank BRI Cabang Gatot Subroto Denpasar sudah memiliki relationship marketing yang baik dengan nasabah. Pernyataan yang memperoleh nilai rata-rata tertinggi terdapat pada pernyataan "Menjaga komitmen yang baik dengan PT Bank BRI" yaitu memiliki skor sebesar 4,23. Hal ini mengindikasikan bahwa PT Bank BRI Cabang Gatot Subroto Denpasar sudah mampu menjaga komitmen yang baik dengan nasabah. Selanjutnya, skor terendah sebesar 3,93 berada pada pernyataan pertama yaitu "Saya menjalin hubungan kepercayaan dengan PT Bank BRI Cabang Gatot Subroto Denpasar", yang mengindikasikan bahwa kurangnya kepercayaan nasabah pada PT Bank BRI. Hal ini mengharuskan pihak manajemen PT Bank BRI Cabang Gatot Subroto Denpasar untuk meningkatkan kepercayaan 
nasabahnya dengan cara membina partnership relations, yakni dengan cara selalu memberikan perhatian contohnya seperti nasabah yang sedang berulang tahun atau merayakan hari besar keagamaan diberikan ucapan selamat dan cindera mata dari PT Bank BRI Cabang Gatot Subroto Denpasar sehingga selalu terjalin hubungan yang baik antara pihak marketing bank dan nasabah.

Variabel Customer Satisfaction diukur dengan menggunakan 4 indikator yang disesuaikan dengan kondisi kepuasan pelanggan di PT Bank BRI Cabang Gatot Subroto Denpasar. Data yang ditunjukan Tabel 6. menampilkan proporsi jawaban responden, rata-rata jawaban, dan kriteria penilaian jawaban responden untuk masing-masing pernyataan pada variabel Customer Satisfaction.

Tabel 6.

Hasil Penilaian Responden atas Variabel Customer Satisfaction

\begin{tabular}{|c|c|c|c|c|c|c|c|c|}
\hline \multirow{2}{*}{ No } & \multirow{2}{*}{ Pernyataan } & \multicolumn{5}{|c|}{ Jawaban } & \multirow{2}{*}{$\begin{array}{c}\text { Rata-rata } \\
\text { Skor }\end{array}$} & \multirow{2}{*}{$\begin{array}{l}\text { Kategori } \\
\text { Penilaian }\end{array}$} \\
\hline & & STS & TS & $\mathbf{N}$ & $\mathbf{S}$ & SS & & \\
\hline 1 & $\begin{array}{l}\text { Merasa puas dengan } \\
\text { sistem keluhan yang } \\
\text { disediakan PT Bank BRI } \\
\text { Cabang Gatot Subroto } \\
\text { Denpasar }\end{array}$ & 0 & 9 & 19 & 65 & 27 & 3,91 & Tinggi \\
\hline 2 & $\begin{array}{l}\text { Merasa puas dengan } \\
\text { sistem go shopping PT } \\
\text { Bank BRI Cabang Gatot } \\
\text { Subroto Denpasar }\end{array}$ & 0 & 10 & 24 & 42 & 44 & 4,00 & Tinggi \\
\hline 3 & $\begin{array}{l}\text { Puas dengan layanan lost } \\
\text { customers analysis di PT } \\
\text { Bank BRI Cabang Gatot } \\
\text { Subroto Denpasar }\end{array}$ & 0 & 1 & 41 & 22 & 56 & 4,11 & Tinggi \\
\hline 4 & $\begin{array}{l}\text { Merasa puas dengan } \\
\text { survey kepuasan nasabah } \\
\text { yang diadakan oleh PT } \\
\text { Bank BRI Cabang Gatot } \\
\text { Subroto Denpasar }\end{array}$ & 0 & 8 & 25 & 40 & 47 & 4,05 & Tinggi \\
\hline & Rata-rata skor variab & cust & er s & fact & & & $\mathbf{3 , 8 6}$ & Tinggi \\
\hline
\end{tabular}

Sumber: Data Primer, diolah (2019)

Tabel 6. menunjukkan nilai total rata-rata jawaban responden sebesar 3,86 yaitu berada pada kategori tinggi. Hal ini memberikan informasi bahwa secara keseluruhan pelanggan pada PT Bank BRI Cabang Gatot Subroto Denpasar sudah memiliki kepuasan yang tinggi. Pernyataan yang memperoleh nilai rata-rata tertinggi terdapat pada pernyataan "Saya puas dengan layanan lost customers analysis di PT Bank BRI Cabang Gatot Subroto Denpasar" dengan skor sebesar 4,11. Selanjutnya skor terendah sebesar 3,91 berada pada pernyataan pertama.

Variabel Customer Satisfaction diukur dengan menggunakan 4 indikator yang disesuaikan dengan kondisi kepuasan pelanggan di PT Bank BRI Cabang Gatot Subroto Denpasar. Data yang ditunjukan Tabel 7. menampilkan proporsi jawaban responden, rata-rata jawaban, dan kriteria penilaian jawaban responden untuk masing-masing pernyataan pada variabel customer satisfaction. 
Tabel 7.

Hasil Penilaian Responden atas Variabel Customer Satisfaction

\begin{tabular}{|c|c|c|c|c|c|c|c|c|}
\hline \multirow{2}{*}{ No } & \multirow{2}{*}{ Pernyataan } & \multicolumn{5}{|c|}{ Jawaban } & \multirow{2}{*}{$\begin{array}{c}\text { Rata-rata } \\
\text { Skor }\end{array}$} & \multirow{2}{*}{$\begin{array}{l}\text { Kategori } \\
\text { Penilaian }\end{array}$} \\
\hline & & STS & TS & $\mathbf{N}$ & $\mathbf{S}$ & SS & & \\
\hline 1 & $\begin{array}{l}\text { Merasa puas dengan } \\
\text { sistem keluhan yang } \\
\text { disediakan PT Bank BRI } \\
\text { Cabang Gatot Subroto } \\
\text { Denpasar }\end{array}$ & 0 & 9 & 19 & 65 & 27 & 3,91 & Tinggi \\
\hline 2 & $\begin{array}{l}\text { Merasa puas dengan } \\
\text { sistem go shopping PT } \\
\text { Bank BRI Cabang Gatot } \\
\text { Subroto Denpasar }\end{array}$ & 0 & 10 & 24 & 42 & 44 & 4,00 & Tinggi \\
\hline 3 & $\begin{array}{l}\text { Puas dengan layanan lost } \\
\text { customers analysis di PT } \\
\text { Bank BRI Cabang Gatot } \\
\text { Subroto Denpasar }\end{array}$ & 0 & 1 & 41 & 22 & 56 & 4,11 & Tinggi \\
\hline 4 & $\begin{array}{l}\text { Merasa puas dengan } \\
\text { survey kepuasan nasabah } \\
\text { yang diadakan oleh PT } \\
\text { Bank BRI Cabang Gatot } \\
\text { Subroto Denpasar } \\
\text { Rata-rata skor varial }\end{array}$ & custo & eer se & 25 & 40 & 47 & 4,05 & Tinggi \\
\hline
\end{tabular}

Sumber: Data Primer, diolah (2019)

Tabel 7. menunjukkan nilai total rata-rata jawaban responden sebesar 3,86 yaitu berada pada kategori tinggi. Hal ini memberikan informasi bahwa secara keseluruhan pelanggan pada PT Bank BRI Cabang Gatot Subroto Denpasar sudah memiliki kepuasan yang tinggi. Pernyataan yang memperoleh nilai rata-rata tertinggi terdapat pada pernyataan "Saya puas dengan layanan lost customers analysis di PT Bank BRI Cabang Gatot Subroto Denpasar" dengan skor sebesar 4,11. Hal ini menunjukkan bahwa sebagian besar pelanggan PT Bank BRI Cabang Gatot Subroto Denpasar sudah merasa puas dengan layanan lost customers analysis. Selanjutnya skor terendah sebesar 3,91 berada pada pernyataan pertama yaitu "Saya merasa puas dengan sistem keluhan yang disediakan PT Bank BRI Cabang Gatot Subroto Denpasar". Hal ini tentu harus menjadi perhatian pihak manajemen PT Bank BRI Cabang Gatot Subroto Denpasar, kritikan dari nasabah terkait tentang keluhan yang disampaikannya kepada nasabah. Manajemen Bank BRI harus sigap dan cepat tanggap dalam mengatasi keluhan yang disampaikan nasabah, seperti penyelesaian kartu ATM terblokir, adanya sceaming ATM yang segera mungkin ditindak lanjuti sehingga nasabah merasa senang bertransaksi di PT Bank BRI Cabang Gatot Subroto Denpasar.

Rekapitulasi penilaian responden mengenai customer loyalty $(\mathrm{Y})$ dapat dilihat pada Tabel 8. sebagai berikut: 
Tabel 8.

Hasil Penilaian Responden atas Variabel Customer Loyalty

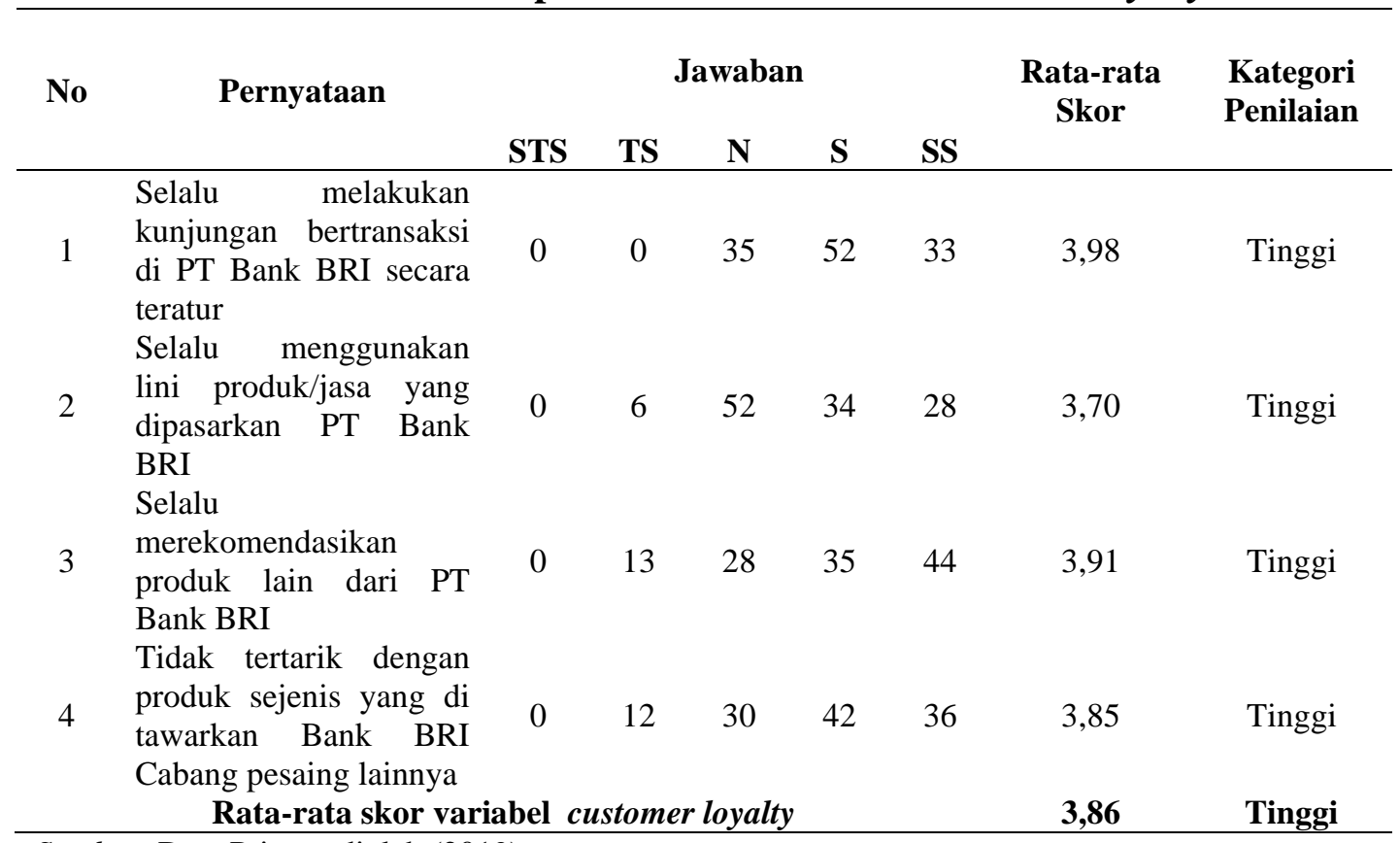

Sumber: Data Primer, diolah (2019)

Tabel 8. menjelaskan persepsi responden mengenai variabel customer loyalty dapat dilihat secara keseluruhan memiliki nilai total rata-rata jawaban responden sebesar 3,86 yang masuk dalam kategori tinggi. Hal ini memberikan informasi bahwa pelanggan pada PT Bank BRI Cabang Gatot Subroto Denpasar sudah memiliki loyalitas yang tinggi. Pernyataan pertama yaitu "Saya selalu melakukan kunjungan bertransaksi di PT Bank BRI Cabang Gatot Subroto Denpasar secara teratur" dengan skor nilai jawaban tertinggi sebesar 3,98 dan skor terendah sebesar 3,70 berada pada pernyataan ke dua yaitu "Saya selalu menggunakan lini produk/jasa yang dipasarkan PT Bank BRI Cabang Gatot Subroto Denpasar". Hal ini harus menjadi prioritas utama bagi pihak manajemen PT Bank BRI Cabang Gatot Subroto Denpasar mengikat masih rendahnya pandangan konsumen terhadap produk/jasa yang ditawarkan, perlu dilakukan sosialisasi berkesinambungan bagi nasabah-nasabah BRI dengan membuat papan pemberitahuan disetiap pintu masuk BRI, melakukan kunjungan yang continue kepada nasabah agar nasabah memahami apa saja yang menjadi produk/jasa unggulan BRI sehingga nasabah nyaman untuk bertransaksi.

Pengujian normalitas nilai residual dalam penelitian ini dilakukan dengan menggunakan metode Kolmogorov-Smirnov. Data dikatakan berdistribusi normal jika taraf signifikansi lebih besar dari 0,05. Dari Tabel 9 diketahui nilai signifikansi sebesar $0,075(0,075>0,05)$. Hal ini berarti model regresi berdistribusi normal.

Uji multikolinearitas digunakan untuk menguji apakah dalam model regresi ditemukan adanya korelasi antar variabel bebas. Jika nilai toleransi lebih kecil dari 
0,1 atau VIF lebih besar dari 10 maka dikatakan tidak ada multikolinearitas. Hasil uji multikolinearitas disajikan pada Tabel 10.

Tabel 9.

Hasil Uji Kolmogorov-Smirnov

\begin{tabular}{llr}
\hline & & $\begin{array}{c}\text { Unstandardized } \\
\text { Residual }\end{array}$ \\
\hline $\mathrm{N}$ & & 120 \\
Normal Parameters(a,b) & Mean & 0,0000000 \\
& Std, Deviation & 1,78469994 \\
Most Extreme Differences & Absolute &, 092 \\
& Positive &, 053 \\
& Negative &,- 092 \\
Kolmogorov-Smirnov Z & & 0,920 \\
Asymp. Sig. (2-tailed) & & 0,075 \\
\hline Sumber: Data Primer, diolah (2019) & &
\end{tabular}

Sumber: Data Primer, diolah (2019)

Tabel 10.

Hasil Uji Multikolinearitas

\begin{tabular}{lcc}
\hline \multicolumn{1}{c}{ Variabel } & Tolerance & VIF \\
\hline Relationship Marketing (X) & 0,672 & 1,487 \\
Customer Satisfaction (M) & 0,675 & 1,482 \\
\hline
\end{tabular}

Sumber: Data Primer, diolah (2019)

Berdasarkan Tabel 10. dapat dilihat bahwa nilai Tolerance masing-masing variabel penelitian pada setiap struktur memiliki nilai lebih dari 0,1 (10 persen) dan nilai VIF yang kurang dari 10. Oleh karena itu berdasarkan nilai Tolerance dan VIF pada model analisis tersebut. Maka dapat disimpulkan bahwa tidak ditemukan adanya gejala multikolinearitas.

Uji heteroskedastisitas bertujuan untuk menguji apakah model regresi terjadi ketidaksamaan varians dari residual pengamatan ke pengamatan yang lain. Jika tingkat signifikansi berada di atas 0,05 maka model regresi ini bebas dari masalah heteroskedastisitas. Hasil uji heteroskedastisitas disajikan pada Tabel 11.

Tabel 11.

Hasil Uji Heteroskedastisitas

\begin{tabular}{lcc}
\hline \multicolumn{1}{c}{ Variabel } & Sig. & Keterangan \\
\hline Relationship Marketing $(\mathrm{X})$ & 0,180 & Bebas heteroskedastisitas. \\
Customer Satisfaction $(\mathrm{M})$ & 0,166 & Bebas heteroskedastisitas \\
\hline
\end{tabular}

Sumber: Data Primer, diolah (2019)

Berdasarkan Tabel 11. dapat dilihat bahwa nilai signifikansi masing-masing variabel lebih besar dari 0,05 yang berarti variabel tersebut bebas heteroskedastisitas. 
Teknik perhitungan dan analisis data menggunakan Moderating Regression Analysis. dengan bantuan program Statistical Package of Social Science (SPSS). Hasil pengujian disajikan dalam hasil uji nilai selisih mutlak pada Tabel 12. berikut ini.

Tabel 12.

Hasil Pelaporan Analisis MRA

\begin{tabular}{|c|c|c|c|c|c|}
\hline \multirow{2}{*}{\multicolumn{2}{|c|}{ Variabel }} & \multicolumn{2}{|c|}{ Koefisien Regresi } & \multirow{2}{*}{$\mathbf{t}$} & \multirow{2}{*}{ Sig } \\
\hline & & B & Std. error & & \\
\hline (constant) & & 0,552 & 0,857 & & \\
\hline Relationship Mark & & 0,526 & 0,050 & 10,480 & 0,000 \\
\hline Customer Satisfact & & 0,452 & 0,055 & 8,200 & 0,000 \\
\hline Relationship Mark & tomer Satisfaction & 0,102 & 0,023 & 2,593 & 0,034 \\
\hline Dependen variabel & : Customer loyalty & & & & \\
\hline F Statistik & $: 130.780$ & & & & \\
\hline Sig F & : 0.000 & & & & \\
\hline $\mathrm{R}^{2}$ & : 0.772 & & & & \\
\hline
\end{tabular}

Sumber : Data Primer, diolah (2019)

Persamaan regresi pada Tabel 12, dapat dijelaskan untuk setiap variabel halhal sebagai berikut:

$$
\mathrm{Y}=0,526 \mathrm{X}+0,452 \mathrm{M}+0,102 \mathrm{XM}
$$

Nilai Koefisien $\beta_{1}$ yang diperoleh sebesar 0,526 menunjukan adanya hubungan variabel relationship marketing dan customer loyalty bersifat positif. Artinya apabila ada peningkatan pada relationship marketing maka akan berpengaruh pada meningkatnya customer loyalty nasabah PT Bank BRI Cabang Gatot Subroto Denpasar.

Nilai Koefisien $\beta_{2}$ yang diperoleh sebesar 0,452 menunjukan adanya hubungan variabel customer satisfaction dan customer loyalty bersifat positif. Artinya apabila ada peningkatan pada customer satisfaction maka akan berpengaruh pada meningkatnya customer loyalty nasabah PT Bank BRI Cabang Gatot Subroto Denpasar.

Nilai Koefisien $\beta_{3}$ yang diperoleh sebesar 0,102 menunjukan adanya hubungan variabel customer satisfaction dan relationship marketing bersifat positif terhadap customer loyalty. Artinya apabila ada peningkatan pada interaksi variabel customer satisfaction dan relationship marketing maka akan berpengaruh pada meningkatnya customer loyalty nasabah PT Bank BRI Cabang Gatot Subroto Denpasar.

Hasil uji statistik $\mathrm{F}$ pada Tabel 12, menunjukan hasil nilai siginifikansi sebesar 0,000 yang lebih kecil dari tingkat $\alpha=0,05$. Hal ini berarti relationship marketing dan customer satisfaction secara bersama berpengaruh signifikan terhadap customer loyalty nasabah PT Bank BRI Cabang Gatot Subroto Denpasar. Hal ini mengindikasikan bahwa model yang digunakan dalam penelitian ini layak dipergunakan.

Pengujian pengaruh secara parsial antara variabel independen dan variabel dependen digunakan uji t. Adapun hasil analisis dari uji t sebagai berikut: Hasil 
perhitungan uji $\mathrm{t}$ dapat dilihat pada Tabel 12. Dari tabel tersebut diketahui bahwa nilai koefisien regresi $\mathrm{X}$ bernilai positif sebesar 0,526 dengan tingkat signifikansi sebesar 0,000 lebih kecil dibandingkan dengan taraf nyata $\alpha=0,05$. Hal ini menunjukan bahwa relationship marketing berpengaruh positif dan signifikan terhadap customer loyalty nasabah PT Bank BRI Cabang Gatot Subroto Denpasar. Semakin baik relationship marketing yang terjalin maka customer loyalty juga semakin meningkat. Hipotesis yang menyatakan bahwa relationship marketing berpengaruh positif terhadap customer loyalty nasabah PT Bank BRI Cabang Gatot Subroto Denpasar diterima.

Hasil perhitungan uji t dapat dilihat pada Tabel 12. Dari tabel tersebut diketahui bahwa nilai koefisien regresi $\mathrm{X}$ adalah sebesar 0,452 dengan tingkat signifikansi sebesar 0,000 lebih kecil dibandingkan dengan taraf nyata $\alpha=0,05$. Hal ini menunjukan bahwa relationship marketing berpengaruh positif dan signifikan terhadap customer loyalty nasabah PT Bank BRI Cabang Gatot Subroto Denpasar. Semakin baik customer satisfaction yang dimiliki nasabah maka customer loyalty juga semakin meningkat. Hipotesis yang menyatakan bahwa customer satisfaction berpengaruh positif terhadap customer loyalty nasabah PT Bank BRI Cabang Gatot Subroto Denpasar diterima.

Hasil perhitungan uji t dapat dilihat pada Tabel 12. Dari tabel tersebut diketahui bahwa nilai koefisien regresi $|Z X M|$ adalah sebesar 0,102 dengan tingkat signifikansi sebesar 0,034 lebih kecil dibandingkan dengan taraf nyata $\alpha=$ 0,05. Hal ini menunjukan bahwa customer satisfaction mampu memoderasi pengaruh positif relationship marketing terhadap customer loyalty nasabah PT Bank BRI Cabang Gatot Subroto Denpasar, artinya semakin baik customer satisfaction seorang nasabah maka terjalinnya relationship marketing yang baik antara nasabah dan Bank BRI sehingga mampu meningkatkan customer loyalty. Hipotesis yang menyatakan bahwa customer satisfaction memoderasi relationship marketing terhadap customer loyalty nasabah PT Bank BRI Cabang Gatot Subroto Denpasar diterima.

Pengujian koefisien determinasi $\left(\mathrm{R}^{2}\right)$ dilakukan untuk mengetahui seberapa besar variasi variabel dependent akan mampu dijelaskan oleh variabel independennya, sedangkan sisanya dijelaskan oleh sebab-sebab variabel lain di luar model (Ghozali, 2011:97). Berdasarkan Tabel 4.11 menunjukan bahwa nilai $\mathrm{R}$ square model adalah 0,772 . Hal ini berarti bahwa sebesar $77,2 \%$ variasi customer loyalty dapat dijelaskan oleh variasi variabel relationship marketing, customer satisfaction dan interaksi dari variabel relationship marketing dengan customer satisfaction, sedangkan sisanya dipengaruhi oleh variabel lain diluar model penelitian.

Berdasarkan hasil analisis data diketahui bahwa relationship marketing berpengaruh positif dan signifikan terhadap customer loyalty nasabah PT Bank BRI Cabang Gatot Subroto Denpasar. Hal ini mengandung arti bahwa semakin baik relationship marketing yang terjalin maka customer loyalty juga semakin meningkat. relationship marketing yang terjalin antara nasabah dengan Bank BRI saat ini harus tetap dipertahankan sehingga memberikan kenyamanan pada setiap nasabah dalam bertransaksi. 
Hasil analisis data menunjukkan customer satisfactionberpengaruh positif dan signifikan terhadap customer loyalty nasabah PT Bank BRI Cabang Gatot Subroto Denpasar.Customer satisfaction atau kepuasan nasabah mengarah kepada profitabilitas, pelanggan yang puas akan menciptakan relationship yang kuat dan mengarah pada loyalitas nasabah.

Hasil penelitian ini searah dengan penelitian Pratiwi dkk., (2014) yang membuktikan kepuasan pelangganmemiliki pengaruh positif dalam meningkatkan loyalitas konsumen. Martini (2013) dalam penelitiannya membukitkan customer satisfaction secara positif mempengaruhi customer loyalty. Framarz et al., (2010) menyatakan customer satisfaction memiliki pengaruh positif dalam meningkatkan loyalitas konsumen. Silvida (2016) membuktikan ada pengaruh positif kepuasan pelanggandalam meningkatkan customer loyalty. Apriliani et al., (2014) menegaskan variabel customer satisfaction memiliki pengaruh positif dalam meningkatkan loyalitas konsumen.

Berdasarkan hasil dari koefisien jalur pada hipotesis penelitian, maka dapat dijabarkan hubungan kausal antar variabel customer satisfaction memoderasi atau memperkuat pengaruh relationship marketing terhadap customer loyalty secara positif di PT Bank BRI Cabang Gatot Subroto Denpasar adalah sebagai berikut:

PT Bank BRI Cabang Gatot Subroto Denpasar sebagai partnership nasabah untuk membantu nasabah bertransaksi, pembukaan rekening tabungan, layanan pinjaman dan masih banyak lagi jasa perbankan yang ditawarkan, untuk membina dan selalu menjalin kerjasama yang baik relationship marketing yang harus dijaga oleh pihak Bank BRI dengan selalu mengedepankan sifat membantu nasabah yang ditunjukkan dari segi perhatian kepada nasabah, selalu mengunjungi nasabah secara berkesinambungan dan yang paling penting adalah perhatian kepada nasabah yang memiliki hari jadi seperti ucapan selamat ulang tahun, selamat hari raya tentunya dengan beberapa hadiah yang disiapkan oleh pihak Bank BRI, hal ini akan membuat terjalinnya hubungan relationship marketing selalu terjaga.

Customer satisfaction nasabah Bank BRI sampai saat ini sudah dapat dikategorikan dengan predikat baik, akan tetapi manajemen harus terus berusaha memberikan yang terbaik kepada nasabah. Hal yang perlu diperhatikan sampai saat ini terkait customer satisfaction sebagai contoh pengaduan nasabah yang harus selalu diperhatikan dengan sikap cepat tanggap sehingga dapat diselesaikan dengan baik yang berakibat akan selalu memuaskan keinginan nasabah dalam kata lain menjaga customer satisfaction nasabah.

Customer loyalty nasabah Bank BRI sampai saat ini sudah dapat dikategorikan dengan predikat baik, akan tetapi manajemen harus terus berusaha memberikan yang terbaik kepada nasabah dalam meningkatkan loyalitas nasabah. Bank BRI telah memasarkan berbagai produk/jasa yang ditawarkan kepada nasabah untuk mendukung nasabah dalam bertransaksi, manajemen Bank BRI harus terus mengedukasi nasabah agar memahami kegunaan produk/jasa yang ditawarkan sehingga memberikan rasa nyaman dan aman kepada nasabah untuk bertransaksi.

Sedangkan keterbatasan penelitian ini yaitu: 1)Penelitian ini hanya meneliti tentang beberapa variabel customer satisfaction, relationship marketing, kedepan agar dikembangkan dengan memilih variabel terbaru yang mempengaruhi 
customer loyalty, selain variabel customer satisfaction, dan relationship marketing. 2)Penelitian hanya memilih satu lokasi penelitian yaitu PT Bank BRI Cabang Gatot Subroto Denpasar. Kedepan dapat dikembangkan dengan memilih lokasi lebih dari satu. 3)Sampel diambil dalam satu waktu tertentu (cross section) sedangkan lingkungan cepat berubah, sehingga penelitian ini penting dilakukan di masyarakat lainnya dengan menambahkan indikator pengaruh lainnya.

\section{SIMPULAN}

Simpulan dari hasil pembahasan adalah Relationship marketing berpengaruh positif dan signifikan terhadap customer loyalty pada PT. Bank BRI Cabang Gatot Subroto Denpasar. Artinya, semakin baik relationship marketing yang terjalin maka customer loyalty nasabah PT. Bank BRI Cabang Gatot Subroto Denpasar akan semakin meningkat. Customer satisfaction berpengaruh positif dan signifikan terhadap customer loyalty pada PT. Bank BRI Cabang Gatot Subroto Denpasar. Artinya, semakin tinggi rasa kepuasan nasabah terhadap pelayanan yang diperoleh dari PT. Bank BRI Cabang Gatot Subroto Denpasar, maka akan semakin meningkatkan sikap loyalitas nasabah. Customer satisfaction memoderasi pengaruh positif relationship marketing terhadap customer loyalty pada PT. Bank BRI Cabang Gatot Subroto Denpasar. Artinya, semakin baik relationship marketing yang dapat terjalin, kemudia ditambah dengan adanya kepuasan nasabah, maka akan memperkuat dampaknya pada customer loyalty nasabah PT. Bank BRI Cabang Gatot Subroto Denpasar.

Sedangkan saran yang dapat diberikan dalam penelitian ini yaitu: Indikator yang memperoleh nilai terendah pada variabel relationship marketing adalah indikator kepercayaan. Maka disarankan bagi Manajemen PT. Bank BRI Cabang Gatot Subroto Denpasar untuk selalu menjalin hubungan kepercayaan yang baik diantara bank dan nasabah, dengan cara selalu memberikan perhatian contohnya seperti nasabah yang sedang berulang tahun atau merayakan hari besar keagamaan diberikan ucapan selamat dan cindera mata dari PT Bank BRI Cabang Gatot Subroto Denpasar sehingga selalu terjalin hubungan yang baik antara nasabah dan nasabah. Indikator yang memperoleh nilai terendah pada variabel customer satisfaction adalah indikator puas dengan sistem keluhan dan saran. Oleh karena itu, disarankan bagi pihak Manajemen PT. Bank BRI Cabang Gatot Subroto Denpasar untuk dapat memperhatikan kritikan nasabah terkait tentang keluhan yang disampaikannya kepada pihak bank. Manajemen Bank BRI harus sigap dan cepat tanggap dalam mengatasi keluhan yang disampaikan nasabah, seperti penyelesaian kartu ATM terblokir, adanya sceaming ATM yang segera mungkin ditindak lanjuti sehingga nasabah merasa senang bertransaksi di PT Bank BRI Cabang Gatot Subroto Denpasar. Indikator yang memperoleh nilai terendah pada variabel costumer loyalty adalah indikator menggunakan lini produk PT. Bank BRI Cabang Gatot Subroto Denpasar, yang mengindikasikan masih rendahnya pandangan nasabah terhadap produk/jasa yang ditawarkan, sehingga perlu dilakukan sosialisasi berkesinambungan bagi nasabah-nasabah BRI dengan membuat papan pemberitahuan disetiap pintu masuk BRI, melakukan kunjungan 
yang continue kepada nasabah agar nasabah memahami apa saja yang menjadi produk/jasa unggulan BRI sehingga nasabah nyaman untuk bertransaksi.

\section{REFERENSI}

Alrubaiee, L., \& Nahla, A.-N. (2010). Investigate the Impact of Relationship Marketing Orientation on Customer Loyalty: The Customer's Perspective. International Journal of Marketing Studies, 2(1), 155-174.

Amalana, A. (2016). Pengaruh Relationship Marketing dan Citra Lembaga Terhadap Loyalitas Nasabah dengan Kepuasan Nasabah sebagai Variabel Moderating (Studi Pada Nasabah Tabungan BPD DIY Syariah Kantor Cabang Yogyakarta). Jurnal Manajemen Strategi Bisnis Dan Kewirausahaan, 9(2), 123-134.

Apriliani, F., Kumadji, S., \& Andriani, K. (2014). Pengaruh Relationship Marketing Terhadap Kepuasan dan Loyalitas Nasabah. Jurnal Administrasi Bisnis, 17(1), 1-5.

Ghozali, I. (2009). Aplikasi Analisis Multivariate dengan Program SPSS. Semarang: Undip.

Handayani, \& Ida, M. (2017). Relationship Marketing memoderasi pengaruh Kualitas Pelayanan terhadap Loyalitas Pelanggan (Nasabah BRI di Semarang). Jurnal Manajemen Dan Kewirausahaan, 3(1), 1-15.

Hurriyati, R. (2010). Bauran Pemasaran dan Loyalitas Konsumen. Bandung: Alfabeta.

Kotler, P., \& Armstrong, G. (2012). Principles of Marketing (14th ed.). New jersey: Prentice Hall.

Kotler, P., \& Keller, K. L. (2007). Manajemen Pemasaran (12th ed.). PT INDEKS.

Luhgiatno, \& Endang, K. (2016). Pengaruh Service Performance dan Relationship Marketing terhadap Loyalitas Konsumen dengan Experiental Marketing sebagai Variabel Moderasi (Studi pada Minimarket di Kota Semarang). Jurnal Fokus Ekonomi, 11(2), 13-36.

Martini, L. K. B. (2013). Relationship Marketing, Customer Satisfaction, Customer Commitment and Customer Loyalty (Study at a National Bank in Denpasar). Jurnal Buletin Studi Ekonomi, 18(1), 9-25.

Pratiwi, U., Suharyono, P., \& Yusri, A. (2014). Pengaruh Relationship Marketing Terhadap Kepuasan dan Loyalitas Nasabah (Studi pada Nasabah Bank Jatim Cabang Pasuruan). Jurnal Administrasi Bisnis, 15(2), 1-9. 
E-Jurnal Manajemen, Vol. 9, No. 5, 2020 : 1656-1675

Silvida, D. R. (2016). Pengaruh Customer Relationship Marketing dan Layanan Purna Jual secara Simultan Terhadap Kepuasan Pelanggan pada Produk Honda Mobilio. Jurnal Manajemen Dan Kewirausahaan, 4(2), 1-84.

Stephen, A. S., Joshua, T. B., \& Robert, W. P. (2014). The Role of Culture in International Relationship Marketing. Journal of Marketing, 7(8), 78-98.

Tjiptono, F. (2011). Strategi Pemasaran (3rd ed.). Yogyakarta: ANDI.

Wachyudi, N. (2018). A Study of the Relationship Marketing Effect in Banks: The Case of an Emerging Market. Journal of Governance \& Regulation, 7(1), 26-39. 